\section{Endoscopic ultrasound-guided transgastric biliary drainage after partial gastrectomy}

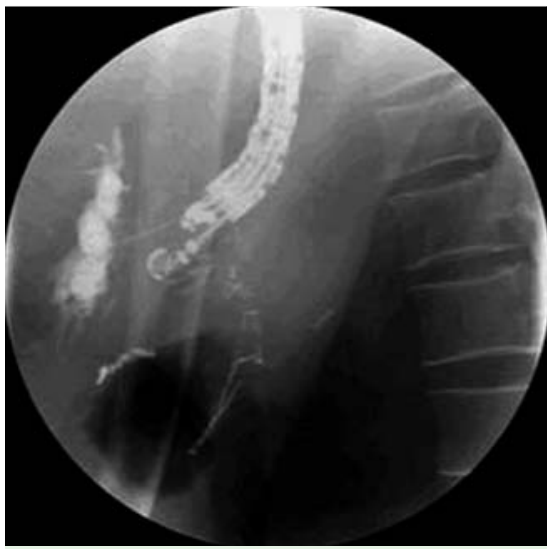

Fig. 1 A puncture made with a $19 \mathrm{G}$ needle into the left intrahepatic bile duct under realtime endoscopic ultrasound monitoring.

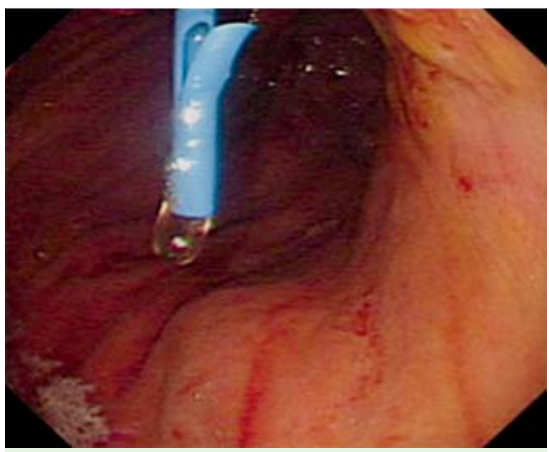

Fig. 2 After stent placement, white bileflowed from the stent.

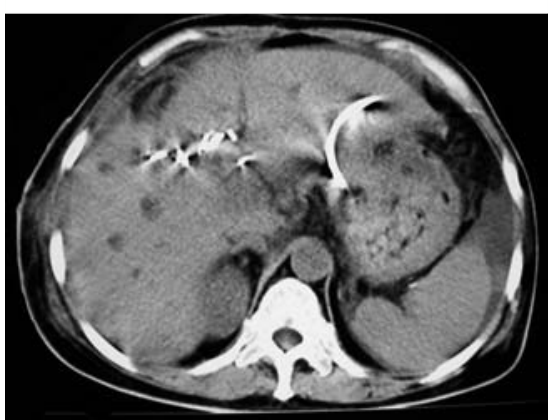

Fig. 3 Computed tomography (CT) scan showing no stent migration after 6 months.
We report a case of endoscopic ultrasound (EUS)-guided transgastric left intrahepatic bile stent drainage after partial gastrectomy for treating cholangiocarcinoma.

A 56-year-old Chinese woman had a 8month history of abdominal pain and jaundice. She had a distal gastrectomy because of cholangiocarcinoma a year ago. Both endoscopic retrograde cholangiopancreatography (ERCP) and percutaneous transhepatic biliary drainage (PTBD) were unsuccessful, so we decided to place a stent under EUS guidance from the remaining stomach to the left intrahepatic bile duct. A left intrahepatic bile duct puncture was made with a $19 \mathrm{G}$ needle. A 0.035-inch yellow, zebra guide wire was introduced through the EUS needle and advanced in an antegrade fashion (๑ Fig. 1)

Afterward, 7 Fr, tapered, biliary, and dilator catheters were inserted over the guide wire and removed, in that order, to dilate the tract. The needle was withdrawn, and an $8.5 \mathrm{~F}$, plastic, single pigtail stent was placed. White bile juice flowed out from the stent ( $\bullet$ Fig. 2).

The procedure was successful and no complications were observed. After a week, the total bilirubin decreased by nearly half. A computed tomography (CT) scan showed that the stent was not displaced ( Fig. 3).

In 1996, Wiersema [1] performed EUSguided cholangiography in seven patients. EUS-guided puncture of the left hepatic ducts via the stomach has been done for cholangiography or in the rendezvous technique. In the present patient we used an 8.5 Fr, plastic, single pigtail stent for 6 months. It was proposed that the plastic stent could be replaced by a covered metallic stent if there was recurrence of the jaundice. Similarly to Vila et al. [2], the main difficulty we found during the exploration was to dilate the gastric wall orifice. This might be due to fibrotic changes in the gastric remnant. In this situation, we found it relatively easy to use hot wire probe hybrid current to expand the puncture point before enlarging the fistula. In our opinion, this technique is a good alternative when ERCP and PTBD are unsuccessful. The limitation is the right hepatic ductal system cannot be fully drained.

\section{Endoscopy_UCTN_Code_TTT_1AS_2AD}

Competing interests: None

\section{J. Ma', Y. Liư $^{2}$, Z. Li², Z. Jin ${ }^{2}$}

Laboratory of Stress Research, Department of Internal Medicine, Changhai Hospital, Second Military Medical University, Shanghai, China

2 Division of Gastroenterology, Department of Internal Medicine, Changhai Hospital, Second Military Medical University, Shanghai, China

\section{References}

1 Wiersema MJ, Sandusky D, Carr R et al. Endosonography-guided cholangiopancreatography. Gastrointest Endosc 1996; 43: $102-$ 106

2 Vila JJ, Go S, Arrazubi V. Endoscopic ultrasonography-guided transgastric biliary drainage aided by Soehendra stent retriever. Am J Gastroenterol 2010; 105: 959-960

Bibliography

DOI $10.1055 / \mathrm{s}-0030-1256104$

Endoscopy 2011; 43: E102

(c) Georg Thieme Verlag KG Stuttgart · New York . ISSN 0013-726X

\section{Corresponding author}

Z. Jin

Division of Gastroenterology

Department of Internal Medicine

Changhai Hospital

Second Military Medical University

Shanghai 200433

China

Fax: +86-21-5562-0081

zhendjin@126.com 